\title{
Mutations of rpoB, katG, inhA and ahp genes in rifampicin and isoniazid-resistant Mycobacterium tuberculosis in Kyrgyz Republic
}

Jainagul Isakova ${ }^{1 *}$ D, Nurmira Sovkhozova ${ }^{1}$, Denis Vinnikov ${ }^{1,2}$, Zoy Goncharova ${ }^{3}$, Elnura Talaibekova ${ }^{1}$, Nazira Aldasheva ${ }^{1,4}$ and Almaz Aldashev ${ }^{1}$

\begin{abstract}
Background: The aim of this study was to identify mutations of rpoB, katG, inhA and ahp-genes associated Mycobacterium tuberculosis resistance to rifampicin (RIF) and isoniazid (INH) in Kyrgyz Republic. We studied 633 smear samples from the primary pulmonary tuberculosis (TB) patients. We verified Mycobacterium tuberculosis susceptibility to RIF and INH using culture method of absolute concentrations, and commercially available test named "TB-BIOCHIP" (Biochip-IMB, Moscow, Russian Federation).

Results: For RIF-resistance, TB-BIOCHIP's sensitivity and specificity were $88 \%$ and $97 \%, 84 \%$ and $95 \%$ for INHresistance, and $90 \%$ and 97\% for multi-drug resistance (MDR). In RIF-resistant strains, TB-BIOCHIP showed mutations in codons 531 (64.8\%), 526 (17.3\%), 516 (8.1\%), 511 (5.4\%), 533 (3.2\%), 522 (0.6\%) and 513 (0.6\%) of rpoB gene. The most prevalent was Ser531 > Leu mutation (63.7\%). $91.2 \%$ of mutations entailing resistance to INH were in katG gene, $7 \%$ in inhA gene, and $1.8 \%$ in $a h p C$ gene. Ser315 $\rightarrow$ Thr (88.6\%) was the most prevalent mutation leading to resistance to $\mathrm{INH}$.

Conclusions: In Kyrgyz Republic, the most prevalent mutation in RIF-resistant strains was Ser531 $\rightarrow$ Leu in rpoB gene, as opposed to Ser315 $\rightarrow$ Thr in katG gene in INH-resistant Mycobacterium tuberculosis. In Kyrgyz Republic, the major reservoir of MDR Mycobacterium tuberculosis were strains with combined mutations Ser $531 \rightarrow$ Leu in rpoB gene and Ser315 $\rightarrow$ Thr in katG gene. TB-BIOCHIP has shown moderate sensitivity with the advantage of obtaining results in only two days.
\end{abstract}

Keywords: Mycobacterium tuberculosis, rpoB, katG, inhA, Ahp, TB-BIOCHIP, Kyrgyz Republic

\section{Background}

Kyrgyzstan is a country in Central Asia with the total population of 6 million, whereas mountainous terrains with poor access to medical care occupy $90 \%$ of its territory. As reported by the WHO, Kyrgyzstan shows high incidence and mortality from TB, and the former peaked in 2001 with 167.8 cases per 100,000 population including penitentiary system patients. TB incidence in Kyrgyzstan that year was 16.8 times the worldwide threshold incidence

\footnotetext{
* Correspondence: jainagul@mail.ru

${ }^{1}$ Institute of Molecular Biology and Medicine, 3 Togolok Moldo street, 720040 Bishkek, Kyrgyzstan

Full list of author information is available at the end of the article
}

of 10.0 per 100,000 . The corresponding mortality rate that year was 27.0 per 100,000 including penitentiary system deaths. Since 2002, there was a consistent reduction in both incidence and mortality from TB in the country. By 2012, the incidence dropped by $37.8 \%$ to 104.3 per 100,000 , whereas $68.1 \%$ reduction in mortality was registered, and the latter equaled 8.6 per 100,000, including penitentiary system patients. During the period of 2012-2016, both incidence and mortality continued to drop. In 2016, 93.1 new cases and 5.8 deaths per 100,000 were reported [1].

Parallel to the overall persistent reduction in $\mathrm{TB}$ incidence, the number of multidrug resistant (MDR) and 
extensive drug resistant (XDR) tuberculosis cases increased. Among all new primary smear-positive pulmonary TB cases in 2015, 26\% were MDR, whereas among previously treated patients this number equaled $54.6 \%[1]$.

Treatment success in MDR TB remains low, reaching only $47-62.7 \%$ [2]. MDR TB is not only a serious clinical and epidemiological problem, but also entails substantial economic costs of management. Thus, treating patients with resistance to the main anti-TB, such as rifampicin (RIF) and isoniazid (INH), may be times more expensive compared to treatment costs incurred by the management of TB susceptible to the main medications panel.

Quite much is known about the mechanisms of resistance to RIF and INH. Thus, Mycobacterium tuberculosis resistance to RIF can be explained by mutations in $r p o B$ gene, whereas katG, inhA, ahpC, kasA and ndh genes mutations are associated with INH resistance [3, 4]. Presentations from around the world report varying geographic distribution of selected mutations of this kind [5], when the most prevalent strains exhibit mutations in codons 531, 526 and 516. In countries with poor epidemiological situation around $\mathrm{TB}$, including former Soviet countries, strains with mutation in codon 531 $($ Ser531 $\rightarrow$ Leu) are the most prevalent $(50-70 \%)$ ones $[6,7]$. On the contrary, this codon mutation in other countries does not exceed 30-48\% [8-10].

We have previously addressed and published the outcomes of our studies addressing genes rpoB, katG, inhA, and ahp mutations [11, 12]. The current analysis presents data on these genes from a larger Mycobacterium tuberculosis DNA sample, as well as the most and the least prevalent RIF- and INH-resistant Mycobacterium tuberculosis strains in Kyrgyz Republic. This updated analysis also includes TB-BIOCHIP specificity and sensitivity data in detecting RIF- and INH-resistant/susceptible Mycobacterium tuberculosis in comparison with a standard culture method.

Therefore, local distribution of drug resistance found in circulating strains should be described based on the molecular studies. In Kyrgyzstan, mutations of rpoB, $k a t G, i n h A$, and $a h p C$ genes have not been studied in local Mycobacterium tuberculosis strains in detail, and major mutations leading to Mycobacteria resistance to RIF and INH have yet to be identified. Therefore, the aim of this study was to describe mutations in $r p o B$, $k a t G$, inh $A$ and $a h p C$ genes and to select the dominating population of RIF and INH-resistant Mycobacterium tuberculosis strains in TB patients living in Kyrgyzstan.

\section{Methods}

\section{Patients and study design}

The study commenced in 2009 and ended in 2011. Patients were recruited from the various inpatient departments of the National Centre of Tuberculosis (NCT), located in Bishkek. Six hundred and thirty-three samples of Mycobacterium tuberculosis were isolated from 633 patients from eight provinces of Kyrgyz Republic, including 192 from Bishkek, 150 from Chuy, 51 from Issyk-Kul, 66 from Naryn, 36 from Talas, 36 from Osh, 69 from Jalalabat, and 33 from Batken.

Tuberculosis diagnosis in recruited patients was confirmed by microscopy and culturing. We considered the following inclusion criteria: TB diagnosed for the first time in life, smear positive microscopic analysis of sputum, age 18 to 70 , inpatient treatment and negative human immunodeficiency virus (HIV) test.

All patients underwent chest X-ray, smear microscopy, supplemented by the bacteriological verification of Mycobacterium tuberculosis at the NCT in Bishkek. This study protocol was approved by the local committee on bioethics of the NCT and the Institute of Molecular Biology and Medicine (Bishkek). All patients in this study provided written informed consent to participate.

In Kyrgyz Republic, on average, there were 1500 new cases of smear-positive TB within the period described in the manuscript. We, therefore, consider the sample size of this study $(N=633)$ sufficient for generalization of the molecular and genetic background of TB identified in Kyrgyzstan.

\section{Data collection}

Sputum samples were collected from patients using conventional methods on the first day of admission to the clinic. Following decontamination, each sputum specimen was divided into two parts. The first portion was used to test Mycobacterium resistance to RIF and INH using classical phenotypic method, whereas the second portion was used to test resistance to RIF and INH using genetic approach, i.e. TB-BIOCHIP.

\section{Bacteriological study and phenotypic drug susceptibility testing (DSTs)}

We used World Health Organization (WHO) recommendations for agent culturing in Lowenstein-Jensen culture medium and first line drug resistance testing via absolute concentrations method [13]. In Kyrgyz Republic, along with the conventional culture method of absolute concentrations with its results available 2-3 months after, they also use automatic «Bactec MGIT 960» test with liquid medium, which shortens result anticipation period to 2-3 weeks.

Whenever we detected the growth of Mycobacterium tuberculosis, Kyrgyz national TB guidelines mandate DSTs using the absolute concentration method on Löwenstein-Jensen medium in the NCT. The corresponding INH and RIF concentrations were $0.2 \mu \mathrm{g} / \mathrm{mL}$ and $40 \mu \mathrm{g} / \mathrm{mL}$. 


\section{Molecular and genetic methods of testing resistance to RIF and INH}

Drug resistance to both RIF and INH was tested using commercially available "TB-BIOCHIP" set (JSC «BIOCHIP-IMB», Moscow, Russian Federation), which was developed by the Institute of molecular biology named after V.A. Engelhard of the Russian Academy of Science (Moscow, Russian Federation). Testing Mycobacterium tuberculosis resistance to RIF and INH using TB-BIOCHIP included the stages of clinical specimen decontamination, germ lysis, two consecutive stage of multiplex PCR, PCR-product (amplicon) hybridization on a biologic microchip, registration, and interpretation. All these stages are described in the product manual [13].

\section{Clinical specimen decontamination and germ lysis}

We used $\mathrm{N}$-acetyl L-cysteine and $3 \% \mathrm{NaOH}$ solution to decontaminate sputum specimens for $40 \mathrm{~min}$ at room temperature. We then resuspended cell extracts in TE buffer and centrifuged them for $10 \mathrm{~min}$, and then exposed the pellet to $30 \mu \mathrm{l}$ of lyses buffer, which contained $1 \%$ TritonX-100, and then incubated it for $20 \mathrm{~min}$ at $95{ }^{\circ} \mathrm{C}$. After that we cooled the extract and centrifuged it for $10 \mathrm{~min}$. Two $\mu \mathrm{l}$ aliquots of supernatant were used for polymerase chain reaction (PCR).

In order to check for possible contamination, we also tested negative control sets of all reagents except target DNA along with the samples in every set of amplification reactions.

\section{Two stages of multiplex PCR}

The first PCR stage was aimed to amplify: a) nucleotide sequence of element IS6110 (309 b.p.), specific for Mycobacterium tuberculosis, and b) rpoB gene (212 b.p.), katG gene (166 b.p.), inhA gene (133 b.p.) and $a h p C$ gene (126 b.p.) fragments, entailing resistance to RIF and INH. The second PCR stage of asymmetric type, aimed at collecting primarily one-chain PCR-products using amplicons from the first stage with simultaneous insertion of fluorescent marker. The second PCR stage was accomplished with primers specific for rpoB gene (126 b. p.), katG gene (140 b.p.), inhA gene (93 b.p.), and $a h p C$ gene (96 b.p.) fragments, as well as IS6110 (110 b.p.). We used primers produced by JSC Biochip-IMB, Moscow, Russian Federation for both the first and second PCR stages [14-16].

\section{On-chip hybridization and microchip analysis}

The corresponding procedure has been described elsewhere in detail [16].

\section{Hybridization outcomes registration}

We tested mutations in $r p o B, k a t G$, inh $A$, and $a h p C$ genes using the fluorescence intensity pattern analysis on the chip with Chipdetector portable fluorescence analyzer. This device works with Imageware software (BIOCHIP-IMB, Moscow, Russian Federation). TB-BIOCHIP can identify mutations in rpoB gene (27 types), katG (11 types), inhA (5 types) and $a h p C$ (5 types), which result in Mycobacterium tuberculosis resistance to RIF and INH.

DNA extraction from clinical samples, PCR amplification of the $r p o B, k a t G$, inhA and $a h p C$ genes, on-chip hybridization and detection of mutations were carried out by the Institute of Molecular Biology and Medicine, Bishkek, Kyrgyz Republic.

\section{Statistical methods}

We compared phenotypic and genetic methods of detecting Mycobacterium tuberculosis resistance and susceptibility to RIF and INH using $2 * 2$ tables. We calculated TB-BIOCHIP sensitivity (ability to detect true resistance) and specificity (ability to detect true sensitivity) using the formulae: specificity $=\mathrm{Tn} /(\mathrm{Tn}+\mathrm{Fp}) \times$ $100 \%$, sensitivity $=\mathrm{Tp} /(\mathrm{Tp}+\mathrm{Fn}) \times 100 \%$, where $\mathrm{Tp}$ is a true positive outcome, $\mathrm{Tn}$ is a true negative outcome, $\mathrm{Fp}$ is a false positive outcome, and $\mathrm{Fn}$ is a false negative outcome [17].

\section{Results}

Patients' age ranged from 18 to 70 years, of whom $60 \%$ were patients in the age group below 40. In total, there were 386 males (61\%) and 247 (39\%) females, with the corresponding male to female ratio $1.5: 1$.

\section{Identification of RIF-resistant and susceptible Mycobacterium tuberculosis using phenotypic DST and biochip}

Cultural method yielded 209 RIF-resistant specimens out of the overall number $N=633$, whereas 424 specimens were susceptible to RIF. Biochip analysis confirmed resistance to RIF in 185 (88\%) specimens out of 209, whereas RIF-susceptibility was confirmed in 411 (97\%) specimens out of 424 . Therefore, TB-BIOCHIP resulted in $88 \%$ sensitivity and $97 \%$ specificity. The overall agreement of two methods in RIF-resistant/susceptible strains identification was $94 \%$ (596 out of 633) (Table 1).

Thirty seven (5.8\%) specimens out of 633 did not match. These discrepancies can be explained with likely mutations in other $r p o B$ gene loci, because TB-BIOCHIP tests only one fragment of $r p o B$ gene, which is a region responsible for RIF-resistance. Mutations explaining RIF-resistance in RRDR locus (81 b.p.), can be identified in $95 \%$ Mycobacterium tuberculosis strains, whereas the gene itself contains 3000 base pairs [3, 4]. 
Table $12 * 2$ table indicating agreement of phenotypic DST with TB-BIOCHIP in RIF-resistant/susceptible strains identification

\begin{tabular}{llll}
\hline TB-BIOCHIP & \multicolumn{2}{l}{ Phenotypic DST } & Total \\
\cline { 2 - 3 } & RIF-resistant & RIF-susceptible & \\
\hline RIF-resistant & 185 & 13 & 198 \\
RIF-susceptible & 24 & 411 & 435 \\
Total & 209 & 424 & 633 \\
\hline
\end{tabular}

\section{Mutations in rpoB gene in RIF-resistant strains}

We found 13 mutations in 7 codons of $r p o B$ gene in RIF-resistant samples $(n=185)$, where the most prevalent locations were codons 531 (64.8\%), 526 (17.3\%), 516 (8.1\%), and 511 (5.4\%), whilst 513, 533 and 522 codons mutations were quite rare (Table 2), altogether explaining only $4.4 \%$ of all rpoB gene mutations. The commonest amino acid replacement was Ser531 $\rightarrow$ Leu in $r p o B$ gene $(63.7 \%)$ cases. The second leading mutation was the one in codon 526 (17.3\%), which comprised five replacement variants, including His526 $\rightarrow$ Tyr (4.3\%), His526 $\rightarrow$ Asp (5.9\%), His526 $\rightarrow$ Arg (5.9\%), His526 $\rightarrow$ Leu $(0.6 \%$, and His $526 \rightarrow$ Pro $(0.6 \%)$. Codon 516 was the third leading location of mutation with two variants: Asp516 $\rightarrow$ Tyr (7.0\%) and Asp516 $\rightarrow$ Val (1.1\%) (Table 2).

\section{Identification of INH-resistant and susceptible Mycobacterium tuberculosis using phenotypic DST and biochip}

Cultural method yielded 135 INH-resistant specimens out of the overall number $N=633$. Biochip analysis confirmed resistance to INH in 114 (84\%) specimens out of 135. Using cultural method, 498 specimens out of 633 were INH-susceptible. Biochip test confirmed INHsusceptibility in 475 (95\%) specimens out of 498. Therefore, TB-BIOCHIP resulted in 84\% sensitivity and 95\% specificity in detecting INH-resistant/susceptible strains. In total, $93 \%$ of INH-resistance/susceptibility outcomes matched (589 out of 633) (Table 3) when two methods were compared.

Forty four (7\%) specimens out of 633 did not match. These discrepancies can be explained with likely mutations in genes other than katG, inhA and $\operatorname{ahpC}$, such as in kasA and $n d h$ genes, which are not tested by the chip [3].

\section{Mutations in katG, inhA and ahpC genes in INH-resistant strains}

As opposed to RIF, INH-resistance may be associated with mutations in a number of genes. 104 (91.2\%) specimens out of 114 yielded strains with katG gene mutations; whereas 8 (7.0\%) specimens had inhA gene and 2 more specimens (1.8\%) had $a h p C$ gene mutations (Table 3). Moreover, in five specimens of INH-resistance, we identified combined mutation of $i n h A$ and $a h p C$ genes. Mutation in codon 315 prevailed in $k a t G$ gene with three mutation variants, including Ser315 $\rightarrow$ Thr (88.6\%), Ser315 $\rightarrow$ Asn $(1.7 \%)$, and Ser315 $\rightarrow$ Arg (0.9\%).

We found nucleotide replacement in position 15 from translation initiation site of inhA gene (inhA $\mathrm{T}_{-}$15). There were also two other mutations found in positions 9 and 12 from translation initiation site in the promotor locus of $a h p C$ gene (ahpC_9 and ahpC_12). In general, INH-resistant strains in Kyrgyz Republic is quite homogenous and is predominantly represented by Ser $\rightarrow$ Thr replacement in codon 315 of katG gene (Table 4).

\section{Identification of MDR Mycobacterium tuberculosis using phenotypic DST and biochip}

Cultural method revealed 174 MDR specimens out of 633, which are resistant to both RIF and INH. Biochip

Table 2 Prevalence and mutation profile in rpoB gene in RIF-resistant strains in Kyrgyzstan

\begin{tabular}{|c|c|c|c|c|c|}
\hline Gene & Codon & Amino acid replacement & Nucleotide replacement & $N=185(\%)$ & $N(\%)$ \\
\hline \multirow[t]{13}{*}{$r p o B$} & 533 & Leu533 $\rightarrow$ Pro & $\mathrm{CTG} \rightarrow \mathrm{CCG}$ & $6(3.2)$ & $6(3.2)$ \\
\hline & \multirow[t]{2}{*}{531} & Ser531 $\rightarrow$ Leu & $\mathrm{TCG} \rightarrow \mathrm{TTG}$ & $118(63.7)$ & \multirow[t]{2}{*}{$120(64.8)$} \\
\hline & & Ser531 $\rightarrow$ Trp & $\mathrm{TCG} \rightarrow \mathrm{TGG}$ & $2(1.1)$ & \\
\hline & \multirow[t]{5}{*}{526} & His526 $\rightarrow$ Tyr & $\mathrm{CAC} \rightarrow \mathrm{TAC}$ & $8(4.3)$ & \multirow[t]{5}{*}{$32(17.3)$} \\
\hline & & His526 $\rightarrow$ Asp & $\mathrm{CAC} \rightarrow \mathrm{GAC}$ & $11(5.9)$ & \\
\hline & & His526 $\rightarrow$ Leu & $\mathrm{CAC} \rightarrow \mathrm{CTC}$ & $1(0.6)$ & \\
\hline & & His526 $\rightarrow$ Arg & $\mathrm{CAC} \rightarrow \mathrm{CGC}$ & $11(5.9)$ & \\
\hline & & His526 $\rightarrow$ Pro & $\mathrm{CAC} \rightarrow \mathrm{CCC}$ & $1(0.6)$ & \\
\hline & 522 & Ser522 $\rightarrow$ Leu & $\mathrm{TCG} \rightarrow \mathrm{TTG}$ & $1(0.6)$ & $1(0.6)$ \\
\hline & \multirow[t]{2}{*}{516} & Asp516 $\rightarrow$ Tyr & $\mathrm{GAC} \rightarrow \mathrm{TAC}$ & $13(7.0)$ & \multirow[t]{2}{*}{$15(8.1)$} \\
\hline & & Asp516 $\rightarrow$ Val & $\mathrm{GAC} \rightarrow \mathrm{GTC}$ & $2(1.1)$ & \\
\hline & 513 & Gln $513 \rightarrow$ Leu & $\mathrm{CAA} \rightarrow \mathrm{CTA}$ & $1(0.6)$ & $1(0.6)$ \\
\hline & 511 & Leu511 $\rightarrow$ Pro & $\mathrm{CTG} \rightarrow \mathrm{CCG}$ & $10(5.4)$ & $10(5.4)$ \\
\hline
\end{tabular}


Table $32 * 2$ table indicating agreement of phenotypic DST with TB-BIOCHIP in INH-resistant/susceptible strains identification

\begin{tabular}{llll}
\hline TB-BIOCHIP & \multicolumn{2}{l}{ Phenotypic DST } & Total \\
\cline { 2 - 3 } & INH-resistant & INH-susceptible & \\
\hline INH-resistant & 114 & 23 & 137 \\
INH-susceptible & 21 & 475 & 496 \\
Total & 135 & 498 & 633 \\
\hline
\end{tabular}

method confirmed MDR in 157 (90\%) out of 174 (Table 5).

Cultural method yielded 459 non-MDR specimens out of the overall number $N=633$. TB-BIOCHIP confirmed non-MDR in 446 (97\%) cases out of 459, and such susceptibility was classified as true susceptibility to RIF and INH. Therefore, TB-BIOCHIP's sensitivity in MDR Mycobacterium tuberculosis identification was 90\%, whereas the specificity was $97 \%$, and the agreement rate was $95 \%$ (603 out of 633) (Table 5).

\section{Mutations in rpoB, katG, inhA and ahpC genes in MDR strains}

MDR is a simultaneous resistance to RIF and INH, usually in $r p o B$ gene leading to RIF-resistance, and katG, inhA or $\operatorname{ahpC}$ genes, associated with INH-resistance. 157 (25\%) specimens in our study were suggestive of MDR. Table 6 shows that $86.6 \%(136 / 157)$ of all MDR cases was a combined mutation in rpoB and katG genes; $2.5 \%(4 / 157)$ cases was a combination of rpoB and $i n h A$ genes mutation, whereas combined mutation in three genes (rpoB, katG and inhA) was found in 10.9\% (17/157) specimens. Dominating mutations were Ser531 $\rightarrow$ Leu replacement in $r p o B$ gene combined with Ser315 $\rightarrow$ Thr replacement in katG gene (50.3\%) (Table 6).

\section{Discussion}

In this study, we confirmed that in TB patients living in Kyrgyz Republic, RIF-resistant Mycobacterium tuberculosis strains had mutations in codons 531, 526, 516, 511, 512,513 and 533 of rpoB gene, whereas the most prevalent were codon 531 (64.8\%) and 526 (17.3\%) mutations.

In INH-resistant Mycobacterium tuberculosis, most common mutations occurred in katG gene (91.2\%), inhA gene $(7 \%)$ and $a h p C$ gene (1.8\%). Amongst all kat $G$ gene mutations, Ser315 $\rightarrow$ Thr replacement in codon 315 was likely the most prevalent. Moreover, we confirmed TBBIOCHIP system has comparable sensitivity and specificity with culture method. Unlike the latter, TB-BIOCHIP can make drug resistance profile available for a clinician within two days, timely guiding epidemiological decision to isolate patients with MDR and correct their treatment almost immediately after the diagnosis.

The majority of RIF-resistant strains in fact have mutation in the so-called "hot" locus of $r p o B$ gene $(81 \mathrm{~b}$. p., codon 507-533 - rifampicin resistance determining region, RRDR). rpoB gene codes beta-subunit of DNA-dependent RNA-polymerase which act as a major target for RIF $[3,18]$. Up to $95-98 \%$ of RIFresistant strains exhibit mutations in $r p o B$ gene, whereas $90-95 \%$ of these mutations are located in RRDR [3, 18]. Despite such miscellaneous mutation locations, most of them are located in three rpoB codons: 531,526 and 516.

In general, our findings of most prevalent codon 531 with Ser531 $\rightarrow$ Leu (64.8\%) replacement in RIF-resistant strains in Kyrgyzstan TB patients somewhat similar to other former Soviet countries and territories with high burden of MDR TB in the prevalence and the profile of rpoB gene mutations [14, 16, 19-24]. In general, Ser531 $\rightarrow$ Leu mutation is the prevalent among RIF-resistant strains, fund all over the world [3].

As opposed to RIF, Mycobacterium tuberculosis resistance to INH is associated with mutations in a number of genes. INH is a pro-drug, and its activation in a cell is performed by catalase-peroxidase, coded by kat $G$ gene in Mycobacterium tuberculosis [25]. INH activation entails a few forms of active oxygen, including superoxide, peroxide and hydroxyl radicals, nitrogen oxide isonicotinic acid radical that act at various targets in Mycobacterium tuberculosis cells, however enol-acidic phosphate-reductase is the principal link in mycolic acids synthesis.

INH-resistance is associated in a number of genes, including katG (catalase-peroxidase gene), kasA ( $\beta$-ketoacyl-ACP-synthase gene), $n d h$ (NADH-dehydrogenase), inhA region (NADH-dependent-ACP-reductase $\operatorname{Inh} A$ gene) and $a h p C$ region (alkyl-hydroxyperoxide-reductase gene). katG and inhA genes mutations are most

Table 4 Prevalence and mutation profile in katG, inhA and ahpC genes in INH-resistant strains in Kyrgyzstan

\begin{tabular}{|c|c|c|c|c|c|}
\hline Gene & Codon & Amino acid replacement & Nucleotide replacement & $N=114(\%)$ & $N(\%)$ \\
\hline \multirow[t]{3}{*}{$\overline{k a t G}$} & 315 & Ser315 $\rightarrow$ Thr & $\mathrm{AGC} \rightarrow \mathrm{ACC}$ & $101(88.6)$ & $104(91.2)$ \\
\hline & & Ser315 $\rightarrow$ Asn & $\mathrm{AGC} \rightarrow \mathrm{AAC}$ & $2(1.7)$ & \\
\hline & & Ser315 $\rightarrow$ Arg & $\mathrm{AGC} \rightarrow \mathrm{CGC}$ & $1(0.9)$ & \\
\hline $\operatorname{inh} A$ & 15 & inhA T_15 & $C \rightarrow T$ & $8(7)$ & $8(7)$ \\
\hline \multirow[t]{2}{*}{$\operatorname{ahpC}$} & 9 & AhpC_9 & $\mathrm{G} \rightarrow \mathrm{A}$ & $1(0.9)$ & $2(1.8)$ \\
\hline & 12 & AhpC_12 & $C \rightarrow T$ & $1(0.9)$ & \\
\hline
\end{tabular}


Table $52 * 2$ table indicating agreement of phenotypic DST with TB-BIOCHIP in MDR strains identification

\begin{tabular}{llll}
\hline TB- & \multicolumn{2}{l}{ Phenotypic DST } & Total \\
\cline { 2 - 3 } BIOCHIP & MDR & non-MDR & \\
\hline MDR & 157 & 13 & 170 \\
non-MDR & 17 & 446 & 463 \\
Total & 174 & 459 & 633 \\
\hline
\end{tabular}

clinically relevant and determine resistance in the most of clinical isolates [3, 26, 27].

Our TB-BIOCHIP tests showed that katG gene mutations were responsible for $91.2 \%$, inh $A$ gene mutations for $7 \%$, and $a h p C$ gene mutations for $1.8 \%$ of resistance to INH. Our findings are quite consistent with the world literature confirming katG gene Ser315 $\rightarrow$ Thr replacement to be the most prevalent $(88.6 \%)$ [19, 28-31]. On the contrary, they found relatively lower katG gene mutations prevalence (less than 40\%) in RIF-resistant strains of Mycobacterium tuberculosis in Tunisia [32, 33].

MDR, which is a combined resistance to RIF and INH, is a serious issue given the economic cost of treatment. Of note, spontaneous chromosome mutations leading to resistance to RIF and INH in a given population have a probability of $3.5 \times 10^{-6}$ and $3.1 \times 10^{-8}[3,4]$, whereas the probability of MDR is times smaller and equals $9 \times 10^{-14}$, since responsible genes are located in different sites. This explains acceptable efficacy of this combination to treat TB in cases when the agent

Table 6 Prevalence and mutation profile in rpoB, katG, inhA and ahpC genes in MDR strains in Kyrgyzstan

\begin{tabular}{|c|c|c|c|c|c|}
\hline \multicolumn{4}{|l|}{ MDR -TB } & \multirow[t]{3}{*}{$N=157$} & \multirow[t]{3}{*}{$\%$} \\
\hline \multirow{2}{*}{$\begin{array}{l}\text { RIF-resistance } \\
\text { rрoB }\end{array}$} & \multicolumn{3}{|l|}{ INH-resistance } & & \\
\hline & katG & $\operatorname{inh} A$ & ahpC & & \\
\hline Ser531 $\rightarrow$ Leu & Ser315 $\rightarrow$ Thr & - & - & 79 & 50.3 \\
\hline Ser531 $\rightarrow$ Leu & Ser315 $\rightarrow$ Thr & InhA_T15 & - & 3 & 1.9 \\
\hline Ser531 $\rightarrow$ Leu & Ser315 $\rightarrow$ Asn & - & - & 5 & 3.2 \\
\hline Ser531 $\rightarrow$ Leu & Ser315 $\rightarrow$ Arg & - & - & 3 & 1.9 \\
\hline His526 $\rightarrow$ Arg & Ser315 $\rightarrow$ Thr & - & - & 7 & 4.5 \\
\hline His526 $\rightarrow$ Asp & Ser315 $\rightarrow$ Thr & - & - & 6 & 3.8 \\
\hline His526 $\rightarrow$ Tyr & Ser315 $\rightarrow$ Thr & InhA_T15 & - & 14 & 9.0 \\
\hline His526 $\rightarrow$ Leu & Ser315 $\rightarrow$ Gly & - & - & 1 & 0.6 \\
\hline His526 $\rightarrow$ Leu & - & InhA_T15 & - & 2 & 1.3 \\
\hline His526 $\rightarrow$ Pro & - & inhA_T15 & - & 1 & 0.6 \\
\hline His526 $\rightarrow$ Asn & - & inhA_T15 & - & 1 & 0.6 \\
\hline Asp516 $\rightarrow$ Tyr & Ser315 $\rightarrow$ Thr & - & - & 13 & 8.3 \\
\hline Asp516 $\rightarrow$ Val & Ser315 $\rightarrow$ Thr & - & - & 2 & 1.3 \\
\hline Leu511 $\rightarrow$ Pro & Ser315 $\rightarrow$ Thr & - & - & 12 & 7.6 \\
\hline Leu533 $\rightarrow$ Pro & Ser315 $\rightarrow$ Thr & - & - & 8 & 5.1 \\
\hline
\end{tabular}

was initially susceptible to these medications [30]. Moreover, resistance to RIF develops the latest, therefore, RIF-resistance is a surrogate marker of MDR [30, 34, 35]. Resistance to RIF alone, however, develops exceptionally seldom, and $90 \%$ of RIFresistance is combined with resistance to INH. Our TB-BIOCHIP tests demonstrated such pattern. Thus, 28 (15\%) specimens out of 185 RIF-resistant strains were resistant to RIF only, whereas 157 (85\%) cases of $r p o B$ gene mutations coincided with $k a t G$, inh $A$ and $a h p C$ genes mutations, usually responsible for INH-resistance.

This analysis has a number of strengths. Firstly, we had an opportunity to take advantage of the use of TBBIOCHIP method to verify mutations in rpoB, katG, inh $A$ and $\operatorname{ahp} C$ gene. The method has been shown to confirm 88\% RIF-resistant and more than 80\% INHresistant strains within a day. Secondly, this study, to our best knowledge, is the first attempt to describe mutations in rpoB, katG, inhA and $a h p C$ genes in Kyrgyz Republic, which can explain MDR to TB. We should also name the opportunity to include patients and specimens from all locations around the country, including low- and high-altitude towns, as another strength of this analysis. Finally, such large sample size may be one of very few reports from this region. As for limitations, we were not able to repeat TB-BIOCHIP analysis after 2 months of treatment once cultural method results were obtained due to technical reasons.

TB-BIOCHIP has been shown to have moderate sensitivity. Its main advantage is the opportunity to obtain fast results, almost within 2 days. The timing and accuracy are essentially important for primary TB patients, when relevant treatment is pivotal to ensure treatment success and immediate segregation of patient groups in order to block the spread of resistant strains and formation of MDR. TB-BIOCHIP helps not only obtain fast results, but also enables to identify genetically opposing RIF and INH-resistant Mycobacterium tuberculosis variants. All these advantages justify the implementation and wide use of TB-BIOCHIP for express detection of RIF- and INH-resistant strains.

With currently moderate sensitivity, the method should be further improved and adapted to clinical practice, since missing $10 \%$ of cases in high TB/MDRTB incidence settings is challenging. Given that the biochip's efficiency depends on the number of available cells for DNA test with at least 500 cells needed, better specimens' collection and preparation may be the way to improve TB-BIOCHIP performance as it may alleviate DNA loss. Our study did not imply TB-BIOCHIP cost effectiveness analysis, however we consider the ability of TB-BIOCHIP to detect MDR Mycobacterium tuberculosis within 2 days as its main advantage. Saving time to the result will 
probably substantially contribute to reducing the cost of patient's management.

At present, a number of molecular and genetic methods of resistance verification are either recommended or in use in various settings. WHO recommends Xpert MBT/ RIF and Genotype MTBDRplus (Hain Lifescience GmbH, Nehren, Germany). Xpert MBT/RIF can verify RIFmutations and, in fact, can only detect Mycobacterium tuberculosis, resistant to RIF only. Genotype MTBDRplus can confirm resistance to two medications, such as RIF and $\mathrm{INH}$, as a result of only three genes mutations, including rpoB, katG and inhA. As opposed to these two options, TB-BIOCHIP can confirm resistance to both RIF and INH resulting from mutations in four genes, including rpoB, katG, inhA and ahp.

We explain the discrepancies between TB-BIOCHIP and Phenotypic DST in detecting susceptibility with a number of reasons including rare mutations, which cannot be verified with the current biochip version; mixed population in a specimen, which may comprise both resistant and susceptible strains, which may show non-homogenous growth in Lowenstein-Jensen culture medium. Moreover, not all mutations will reflect phenotypic changes when cultivating strains in a solid culture medium with set concentrations of medications. Finally, TB-BIOCHIP can detect mutations associated with RIFand INH-mutations in both alive and dead Mycobacterium tuberculosis.

\section{Conclusions}

In Kyrgyz Republic, Ser531 $\rightarrow$ Leu replacement in rpoB gene was the commonest variant of RIF-resistance, whereas Ser315 $\rightarrow$ Thr mutation in katG gene could likely explain most of INH-resistance using TBBIOCHIP analysis. MDR strains in our country likely developed most of their resistance because of combined mutations Ser531 $\rightarrow$ Leu in $r$ ro B gene and Ser315 $\rightarrow$ Thr in $k a t G$ gene. Taken together, this analysis will help guide treatment of patients with resistant strains and reduce the overall burden of the disease in the country.

\section{Abbreviations \\ DNA: deoxyribonucleic acid; HIV: human immunodeficiency virus; INH: isoniazid; MDR: multi-drug-resistant; NCT: National Centre of Tuberculosis; RIF: rifampicin; USSR: Union of Soviet Socialist Republics; WHO: World Health Organization}

\section{Acknowledgements}

Not applicable.

\section{Funding}

This work was supported by the International Science and Technology Center [project \#KR-1596]. The funding body was not involved in the design of the study and collection, analysis, and interpretation of data, as well as and in writing the manuscript.
Availability of data and materials

The datasets used and/or analysed during the current study are available from the corresponding author on reasonable request.

\section{Authors' contributions}

$\mathrm{Jl}, \mathrm{NA}$, and AA conceived and designed the experiments. JI, NS and ET carried out the biochip analysis and performed the statistical analysis. J and DV wrote the paper. JI, ZG and AA undertook data collection, interpretation of results and edited the manuscript. All authors read and approved the final manuscript.

\section{Ethics approval and consent to participate}

This study protocol was approved by the local committee on bioethics of the NCT and the Institute of Molecular Biology and Medicine (Bishkek).

All patients in this study provided written informed consent to participate.

\section{Consent for publication}

Not applicable.

\section{Competing interests}

The authors declare that they have no competing interests.

\section{Publisher's Note}

Springer Nature remains neutral with regard to jurisdictional claims in published maps and institutional affiliations.

\section{Author details}

${ }^{1}$ Institute of Molecular Biology and Medicine, 3 Togolok Moldo street, 720040 Bishkek, Kyrgyzstan. ${ }^{2}$ School of Public Health, Al-Farabi Kazakh National University, Al-Farabi avenue 71, Almaty, Kazakhstan 050040. ${ }^{3}$ National Center of Tuberculosis, 90a, Akhunbaev street, Bishkek 720020, Kyrgyz Republic. ${ }^{4}$ Kyrgyz-Russian Slavic University, Bishkek44 Kievskaya street, Bishkek 720000, Kyrgyz Republic

Received: 27 September 2017 Accepted: 19 March 2018

Published online: 22 March 2018

References

1. Kadyrov AS. Tuberculosis epidemic in the Kyrgyz Republic in 2012-2016. Sci New Technol Innov Kyrg. 2017:3-7.

2. Organization WH. Global tuberculosis report 2016. 2016;

3. Ramaswamy S, Musser JM. Molecular genetic basis of antimicrobial agent resistance inMycobacterium tuberculosis: 1998 update. Tuber Lung Dis. 1998;79:3-29.

4. Telenti A, Imboden P, Marchesi F, Matter L, Schopfer K, Bodmer T, et al. Detection of rifampicin-resistance mutations in Mycobacterium tuberculosis. Lancet. 1993:341:647-51.

5. Rosales-Klintz S, Jureen P, Zalutskayae A, Skrahina A, Xu B, Hu Y, et al. Drug resistance-related mutations in multidrug-resistant Mycobacterium tuberculosis isolates from diverse geographical regions. Int J Mycobacteriology. 2012;1:124-30.

6. Jiao W-W, Mokrousov I, Sun G-Z, Li M, Liu J-W, Narvskaya O, et al. Molecular characteristics of rifampin and isoniazid resistant Mycobacterium tuberculosis strains from Beijing. China Chin Med J (Engl). 2007:120:814-9.

7. Jo K-W, Lee S, Kang MR, Sung H, Kim M-N, Shim TS. Frequency and type of disputed rpoB mutations in Mycobacterium tuberculosis isolates from South Korea. Tuberc Respir Dis. 2017;80:270-6

8. Adikaram CP, Perera J, Wijesundera SS. Geographical profile of rpoB gene mutations in rifampicin resistant Mycobacterium tuberculosis isolates in $\mathrm{Sr}$ Lanka. Microb Drug Resist. 2012:18:525-30.

9. Minh NN, Van Bac N, Son NT, Lien VTK, Ha CH, Cuong NH, et al. Molecular characteristics of rifampin-and isoniazid-resistant Mycobacterium tuberculosis strains isolated in Vietnam. J Clin Microbiol. 2012;50:598-601.

10. Sajduda A, Brzostek A, Popławska M, Augustynowicz-Kopeć E, Zwolska Z, Niemann S, et al. Molecular characterization of rifampin-and isoniazidresistant Mycobacterium tuberculosis strains isolated in Poland. J Clin Microbiol. 2004:42:2425-31.

11. Isakova Z. Distribution of mutations in the rpoB, katG, inhA, ahpC gene of rifampicin and isoniazid resistant M. tuberculosis strains isolated in Kyrgyz Republic. Mol. Genet. Mikrobiol. Virusol. 2008;4:36-8. 
12. Mokrousov I, Isakova J, Valcheva V, Aldashev A, Rastogi N. Molecular snapshot of Mycobacterium tuberculosis population structure and drugresistance in Kyrgyzstan. Tuberculosis. 2013;93:501-7.

13. Crofton SJ, Chaulet P, Maher D, Grosset J, Harris W, Horne N, et al. Guidelines for the management of drug-resistant. Tuberculosis. WHO; 1997.

14. Gryadunov D, Mikhailovich V, Lapa S, Roudinskii N, Donnikov M, Pan'kov S, et al. Evaluation of hybridisation on oligonucleotide microarrays for analysis of drug-resistant Mycobacterium tuberculosis. Clin Microbiol Infect. 2005;11:531-9.

15. Gryadunov D, Dementieva E, Mikhailovich V, Nasedkina T, Rubina A, Savvateeva E, et al. Gel-based microarrays in clinical diagnostics in Russia. Expert Rev Mol Diagn. 2011;11:839-53.

16. Mikhailovich V, Lapa S, Gryadunov D, Sobolev A, Strizhkov B, Chernyh N, et al. Identification of rifampin-resistant Mycobacterium tuberculosis strains by hybridization, PCR, and ligase detection reaction on oligonucleotide microchips. J Clin Microbiol. 2001;39:2531-40.

17. Altman DG, Bland JM. Diagnostic tests. 1: sensitivity and specificity. BMJ. 1994;308:1552

18. Telenti A. Genetics of drug resistance in tuberculosis. Clin Chest Med. 1997; 18:55-64.

19. Khan SN, Niemann S, Gulfraz M, Qayyum M, Siddiqi S, Mirza ZS, et al. Molecular characterization of multidrug-resistant isolates of Mycobacterium tuberculosis from patients in Punjab, Pakistan. Pak J Zool. 2013;45:93-100.

20. Poudel A, Nakajima C, Fukushima Y, Suzuki H, Pandey BD, Maharjan B, et al. Molecular characterization of multidrug-resistant Mycobacterium tuberculosis isolated in Nepal. Antimicrob Agents Chemother. 2012;56:2831-6.

21. Rahim Z, Nakajima C, Raqib R, Zaman K, Endtz HP, van der Zanden AG, et al. Molecular mechanism of rifampicin and isoniazid resistance in Mycobacterium tuberculosis from Bangladesh. Tuberculosis. 2012;92:529-34.

22. Thirumurugan R, Kathirvel M, Vallayyachari K, Surendar K, Samrot AV, Muthaiah M. Molecular analysis of rpoB gene mutations in rifampicin resistant Mycobacterium tuberculosis isolates by multiple allele specific polymerase chain reaction in Puducherry, South India. J. Infect. Public Health. 2015;8:619-25.

23. Yao C, Zhu T, Li Y, Zhang L, Zhang B, Huang J, et al. Detection of rpoB, katG and inhA gene mutations in Mycobacterium tuberculosis clinical isolates from Chongqing as determined by microarray. Clin Microbiol Infect. 2010;16:1639-43.

24. Yoon J-H, Nam J-S, Kim K-J, Choi Y, Lee H, Cho S-N, et al. Molecular characterization of drug-resistant and-susceptible Mycobacterium tuberculosis isolated from patients with tuberculosis in Korea. Diagn Microbiol Infect Dis. 2012;72:52-61.

25. Zhang Y, Heym B, Allen B, Young D, Cole S. The catalase-peroxidase gene and isoniazid resistance of Mycobacterium tuberculosis. Nature. 1992;358: 591-3.

26. Kelley $\mathrm{CL}$, Rouse DA, Morris SL. Analysis of ahpC gene mutations in isoniazid-resistant clinical isolates of Mycobacterium tuberculosis. Antimicrob Agents Chemother. 1997;41:2057-8.

27. Lee AS, Teo AS, Wong S-Y. Novel mutations in ndh in isoniazid-resistant Mycobacterium tuberculosislsolates. Antimicrob Agents Chemother. 2001;45: 2157-9.

28. Lin HH, Kim H-Y, Yun Y-J, Park CG, Kim B-J, Park Y-G, et al. Mutations of katG and inhA in MDR M. Tuberculosis. Tuberc. Respir. Dis. 2007;63:128-38.

29. Mokrousov I, Otten T, Filipenko M, Vyazovaya A, Chrapov E, Limeschenko E, et al. Detection of isoniazid-resistant Mycobacterium tuberculosis strains by a multiplex allele-specific PCR assay targeting katG codon 315 variation. J Clin Microbiol. 2002;40:2509-12.

30. Ravibalan T, Maruthai K, Samrot AV, Muthaiah M. Characterization of katG and rpoB gene mutations in multi drug resistant Mycobacterium tuberculosis clinical isolates. Int J Curr Microbiol Appl Sci. 2014;3:1072-80.

31. Unissa AN, Selvakumar N, Narayanan S, Suganthi C, Hanna LE. Investigation of Ser315 substitutions within katG gene in isoniazid-resistant clinical isolates of Mycobacterium tuberculosis from South India. Biomed Res Int 2015;2015

32. Prammananan T, Cheunoy W, Taechamahapun D, Yorsangsukkamol J, Phunpruch S, Phdarat $P$, et al. Distribution of rpoB mutations among multidrug-resistant Mycobacterium tuberculosis (MDRTB) strains from Thailand and development of a rapid method for mutation detection. Clin Microbiol Infect. 2008;14:446-53.
33. Soudani A, Hadjfredj S, Zribi M, Messaadi F, Messaoud T, Masmoudi A, et al. Genotypic and phenotypic characteristics of tunisian isoniazid-resistant Mycobacterium tuberculosis strains. J Microbiol. 2011;49:413-7.

34. Li D, Song Y, Zhang C-L, Li X, Xia X, Zhang A-M. Screening mutations in drug-resistant Mycobacterium tuberculosis strains in Yunnan, China. J Infect Public Health. 2017;

35. Li Q, Jiao W, Yin Q, Li Y, Li J, Xu F, et al. Positive epistasis of major low-cost drug resistance mutations rpoB531-TTG and katG315-ACC depends on the phylogenetic background of Mycobacterium tuberculosis strains. Int J Antimicrob Agents. 2017:49:757-62.

\section{Submit your next manuscript to BioMed Central and we will help you at every step:}

- We accept pre-submission inquiries

- Our selector tool helps you to find the most relevant journal

- We provide round the clock customer support

- Convenient online submission

- Thorough peer review

- Inclusion in PubMed and all major indexing services

- Maximum visibility for your research

Submit your manuscript at www.biomedcentral.com/submit
) Biomed Central 